\title{
ARISTA: APPLICATION OF REPORTING INFORMATION SYSTEM AT FTK UNDIKSHA
}

\author{
Kade Arista Anggisavitri ${ }^{1)}$, I Ketut Resika Arthana2), I Gede Mahendra Darmawiguna ${ }^{3)}$ \\ ${ }^{1}$ Fakultas Teknik dan Kejuruan, Universitas Pendidikan Ganesha \\ 2 Fakultas Teknik dan Kejuruan, Universitas Pendidikan Ganesha \\ ${ }^{3}$ Fakultas Teknik dan Kejuruan, Universitas Pendidikan Ganesha \\ Email: aristaanggisavitri@gmail.com, resika@undiksha.ac.id, mahendra.darmawiguna@undiksha.ac.id
}

\begin{abstract}
ABSTRAK
Penelitian ini bertujuan: Membuat rancang bangun dan mengembangkan ARISTA (Application of Reporting Informastion System FTK Undiksha); mengetahui respon sivitas akademika FTK terhadap ARISTA (Application of Reporting Informastion System at FTK Undiksha). Untuk memberikan pelayanan yang baik bagi civitas akademikanya, FTK memberikan kesempatan kepada sivitasnya untuk memberikan masukan baik kritik maupun saran terkait pelayan yang diberikan. Aplikasi ARISTA akan mewadahi semua keluhan baik kritik maupun saran yang berhubungan dengan pihak jurusan maupun fakultas. Aplikasi ini membagi cakupan permasalahan menjadi 2 yaitu, pengaduan ke jurusan atau pengaduan ke fakultas. Jenis penelitian ini adalah penelitian pengembangan dengan model Analysis, Design, Development, Implementation, and Evaluation (ADDIE).

Implementasi penelitian ini diterapkan dengan menggunakan framework React-Native pada aplikasi mobile dan menggunakan bahasa pemrograman PHP dengan bantuan framework Laravel pada aplikasi web. Untuk proses pengujian, dilakukan lima (5) tahap proses pengujian yaitu: Uji blackbox untuk mengetahui apakah seluruh fungsional perangkat lunak sudah sesuai dan hasilnya sebesar $100 \%$ baik; uji whitebox yang menyatakan bahwa implementasi source code sesuai dan tanpa error; uji pengalaman pengguna menggunakan metode UEQ untuk mengetahui pengalaman pengguna setelah mengunakan aplikasi ARISTA; uji compatibility yang menyatakan aplikasi ARISTA bisa digunakan pada perangkat dengan merek dan sistem operasi Android yang berbeda; uji keamanan yang dilakukan dengan SQL Injection sebanyak 4 kali menyatakan bahwa aplikasi ARISTA aman.
\end{abstract}

Kata kunci: Aplikasi Mobile, Pengaduan, FTK, Undiksha, React-Native

\begin{abstract}
This research aimed: To create the design and development of ARISTA (Application of Reporting Information System FTK Undiksha); to know the responsiveness of FTK academicians towards ARISTA (Application of Reporting Information System FTK Undiksha). In providing a good service for the academic community, FTK gives an opportunity to the FTK's civitas academica to provide input both criticism and suggestions related to the given service. ARISTA will accommodate all complaints both criticism and advice related to the department and faculty. For this application is divided into 2 terms, such as complaint to the department or complaint to the faculty. The type of this research is research and development with model Analysis, Design, Development, Implementation, and Evaluation (ADDIE).

Implementation of this research is applied by using React-Native framework in mobile application and using PHP programming language with the as-sist of Laravel framework on web application. For the testing process, five (5) test process stages are performed: Black box test to determine whether all software is appropriate; white box test that implies implementation code no error; user experience test using UEQ method To know the user experience after using the ARISTA; compatibly test stating the ARISTA can be used on devices with different devices and operations; the security test stating the ARISTA is relatively safe.
\end{abstract}

Keywords : Mobile Application, Complaint, FTK, Undiksha, React-Native 


\section{PENDAHULUAN}

Universitas Pendidikan Ganesha yang selanjutnya disebut Undiksha merupakan perguruan tinggi yang bertanggung jawab kepada Kementrian Riset Teknologi dan Pendidikan Tinggi, berkedudukan di Singaraja, Provinsi Bali. Sebagai salah satu universitas pendidikan terbesar di Bali, Undiksha menawarkan beberapa kesempatan untuk belajar tentang masing-masing disiplin pengetahuan dan sistem pendidikan. Dalam menopang proses pembelajaran tersebut Undiksha sudah menyiapkan segala hal baik itu dari segi pelayanan akademik, pelayanan sarana berupa fasilitas-fasilitas yang sangat memadai, dan pelayanan di bagian kemahasiswaan untuk seluruh civitas akademika Undiksha. [1] Saat ini Undiksha terbagi menjadi tujuh Fakultas salah satunya yaitu Fakultas Teknik dan Kejuruan (FTK). Setiap fakultas tentu memiliki visi dan misi yang menggambarkan tujuan yang hendak dicapai yang tentunya untuk menjadikan fakultas lebih baik dan lebih berkualitas. Seperti salah satu misi dari FTK adalah menyelenggarakan pendidikan yang efektif dalam bentuk layanan yang mampu memuaskan mahasiswa di bidang teknologi dan kejuruan untuk mendukung kemajuan dan pengembangan masyarakat yang berlandaskan Tri Hita Karana. Berdasarkan misi tersebut FTK berupaya memberikan pelayanan yang optimal demi memuaskan mahasiswanya [2].

FTK selalu mengadakan audiensi untuk mendengarkan keluhan atau pengaduan terkait pelayanan yang belum memuaskan dari segi akademik, sarana prasa-rana, maupun kemahasiswaan. Kegiatan audiensi ini dihadiri oleh staff dosen dan mahasiswa untuk menyampaikan keluhan apabila masih ada pelayanan yang kurang atau perlu adanya perbaikan. Meskipun demikian kegiatan audiensi ini masih memiliki kekurangan yaitu waktu yang terbatas dalam menyampaikan semua keluhan dan tidak semua mahasiswa atau staff dosen bisa menghadiri kegiatan tersebut. Karena penyampaian keluhan secara transparan hanya bisa dilakukan ketika audiensi berlangsung jadi masukan dan keluhan oleh sivitas FTK tidak bisa ditangani secara optimal.

Peneliti telah melakukan diskusi dengan seluruh Wakil Dekan FTK terkait pelayanan yang ada di FTK. Bapak Dr. Komang Setemen, , S.Si., M.T selaku Wakil Dekan II menyatakan bahwa FTK telah berupaya memberikan fasilitas yang baik untuk menopang seluruh kegiatan civtas FTK, baik itu kegiatan perkuliahan maupun nonperkuliahan. Namun tentunya masih perlu adanya evaluasi terkait fasilitas yang telah disediakan. Ibu Cok. Istri Raka Marsiti, S.Pd., M.Pd. selaku Wakil Dekan III menyatakan bahwa pada dasarnya masukan dari seluruh civitas itu sangat diperlukan, karena hal ini bisa menjadi bahan pertimbangan agar kampus menjadi lebih baik dan proses pembelajaran menjadi lebih berkualitas. Sebagai warga kampus yang baik, sudah seharusnya ikut berperan aktif melakukan pengawasan dan memonitor semua fasilitas yang ada.

Atas rekomendasi dari Bapak Dr. Gede Rasben Dantes, S.T., M.T.I selaku Wakil Dekan I, peneliti juga telah berdiskusi dengan Bapak Putu Tegeh, S.E. yang merupakan Kasubag Akademik di FTK. Beliau menyebutkan bahwa pelayanan dari bidang akademik sudah berjalan secara optimal, namun masih ada sedikit permasalahan yang perlu ditinjau seperti permasalahan mata kuliah yang diajarkan oleh Dosen Kontrak, kemudian pembuatan SK yang salah karena permasalahan nama belum valid dan sebagainya. Bapak Dr. Gede Rasben Dantes, S.T., M.T.I juga menyebutkan bahwa permasalahan yang biasanya muncul dari bidang akademik seperti adanya perubahan nilai, nilai belum masuk, permasalahan dengan dosen pembimbing dalam menyelesaikan tugas akhir, dan sebagainya. Untuk itu perlu adanya masukan dan partisipasi sivitas FTK ketika menemukan permasalahan dalam bidang akademik agar segera melaporkan untuk mempercepat layanan akademik.

Sejalan dengan diskusi yang telah dilakukan bersama Wakil Dekan FTK dan Kasubag Akademik untuk membantu dan mempermudah seluruh civitas FTK berpartisipasi secara aktif dalam membangun Undiksha secara langsung diperlukan suatu aplikasi. Aplikasi dengan biaya yang relative murah dan bisa diakses menggunakan perangkat yang umum digunakan yaitu smartphone maupun tablet phone. Sehingga dalam mengelola fasilitas maupun lingkungan kampus khususnya fakultas, tidak hanya Wakil Dekan beserta staf saja namun harus didukung oleh mahasiswa dan staf dosen yang peduli dengan kemajuan fakultasnya.

Berdasarkan pada permasalahan tersebut maka peneliti tertarik untuk mengangkat suatu penelitian yang berjudul "PENGEMBANGAN ARISTA (Application of Reporting Information System FTK Undiksha)" dengan studi kasus yaitu Fakultas Teknik dan Kejuruan (FTK). 


\section{METODE}

Pengembangan Aplikasi ARISTA (Application of Reporting Information System FTK Undiksha) ini akan menggunakan metode Analysis, Design, Development, Implementation and Evaluation (ADDIE). ADDIE adalah model perancangan instruksional yang berupa proses umum yang secara tradisional digunakan oleh perancang instruksional ataupun pengembangan pelatihan dan aplikasi.

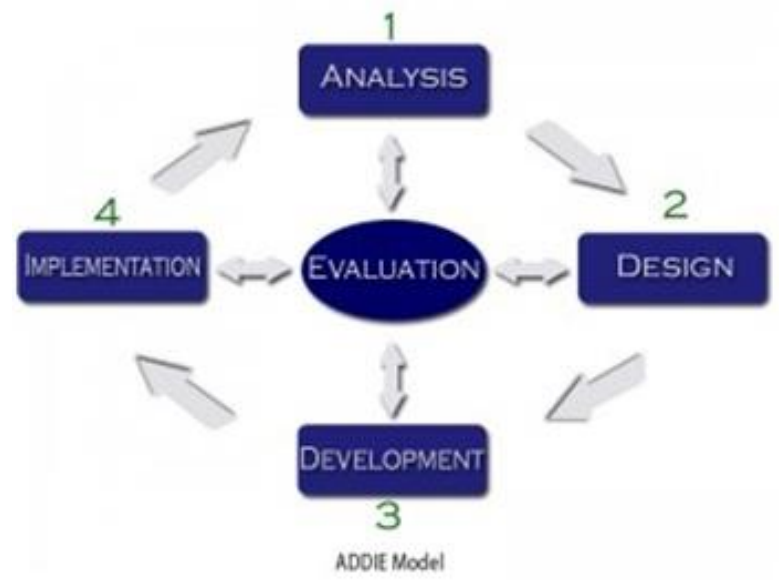

Gambar 1 Tahapan Model ADDIE

Selama fase analisis, pertama peneliti melakukan analisis masalah terhadap kekurangan kegiatan audiensi yang diadakan FTK untuk mendengarkan keluhan terkait pelayanan FTK. Dari kekurangan tersebut peneliti menawarkan solusi dikembangkannya aplikasi ARISTA. Selanjutnya, peneliti melakukan analisis dengan studi literature, diskusi dan wawancara, serta pengumpulan data menggunakan angket. Berdasarkan hasil analisis yang dilakukan, peneliti selanjutnya merancang kebutuhan fungsional dan non fungsional menggunakan pemodelan use case dan activity diagram. Dalam proses pertukaran data dan informasi menggunakan arsitektur client-server. Kemudian peneliti melakukan perancangan perangkat lunak mulai dari batasan perangkat lunak, struktur navigasi, antarmuka, arsitektur perangkat lunak, dan struktur data sebelum mengimplementasikannya. Tahapan yang ketiga yaitu melakukan pengembangan aplikasi dari desain perangkat lunak yang telah dilakukan sebelumnya. Pengembangan aplikasi ini di lakukan menggunakan React-Native agar nantinya aplikasi ini dapat di compile ke berbagai Platform.

\section{A. Analisis Perangkat Lunak}

Selama fase analisis peneliti melakukan studi literature terhadap aplikasi terkait dan penelitian terkait yang sudah sebelumnya, kemudian diskusi dan wawancara dengan pimpinan FTK, serta menyebarkan angket kepada calon pengguna untuk menjelaskan tujuan da alur aplikasi yang akan dikembangkan berserta dengan fitur-fitur yang akan dikembangkan. Dalam hal ini responden diminta untuk menjawab beberapa pertanyaan untuk memvalidasi apakah fitur-fitur yang desbutkan pada angket sudah sesuai dengan kebutuhan atau belum. Hasil dari analisis berupa kebutuhan fungsional dan kebutuhan non fungsional.

\section{B. Model Fungsional Perangkat Lunak}

Pemodelan fungsional perangkat lunak menggunakan UML (Unified Modeling Language). Unified Modelling Language (UML) adalah sebuah "bahasa" yang telah menjadi standar dalam industri untuk menentukan, visualisasi,merancang dan mendokumentasikan artifact dari sistem software, untuk memodelkan bisnis dan sistem non software lainnya. UML merupakan suatu kumpulan teknik terbaik yang telah terbukti sukses dalam pemodelan sitem yang besar dan kompleks. [12]. Berikut merupakan use case diagram dari Aplikasi ARISTA berdasarakan kebuthan fungsional dan kebutuhan non fungsional. 


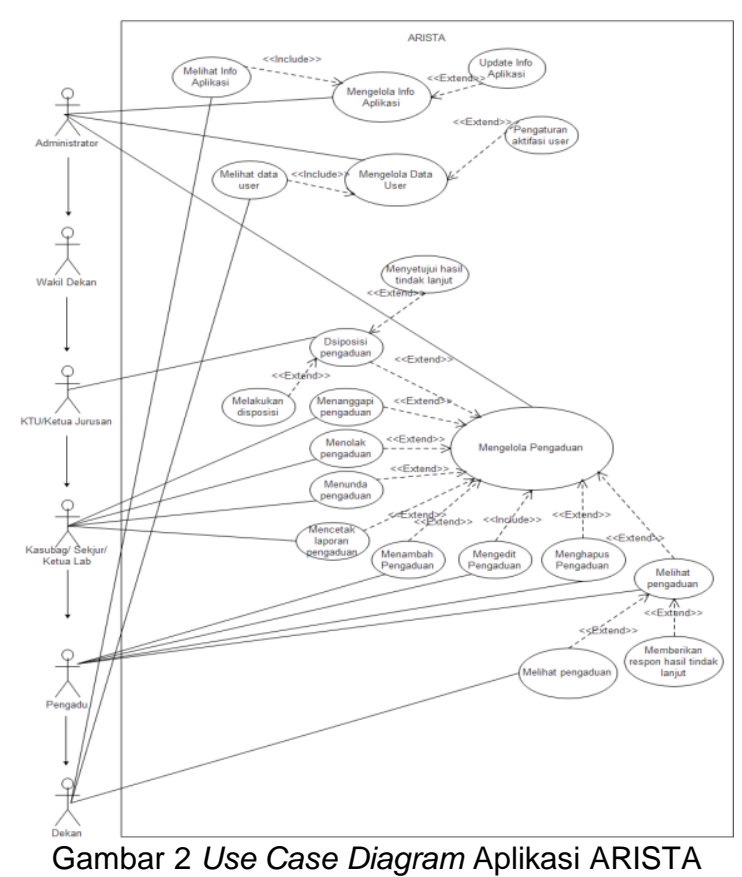

\section{Struktur Navigasi Sistem}

Adapun struktur navigasi dari aplikasi ARISTA sebagai berikut.

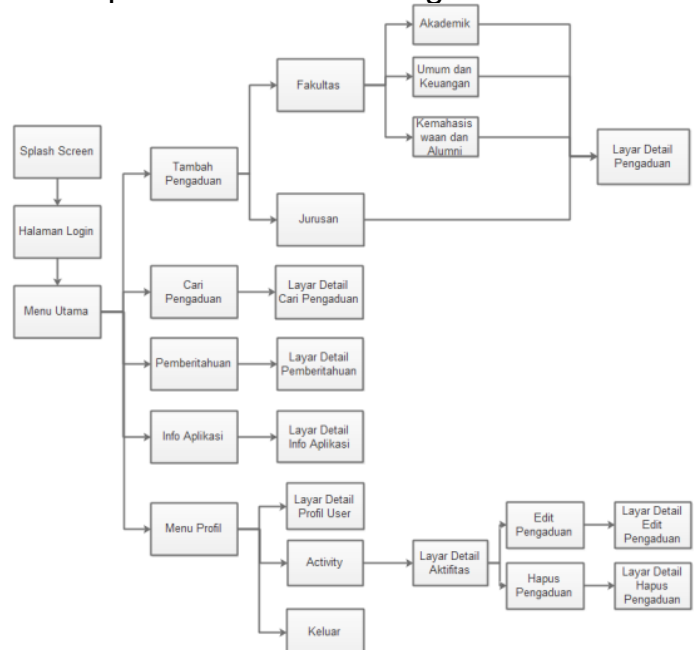

Gambar 3 Strukur Navigasi Aplikasi ARISTA

\section{Rancangan Arsitektur Aplikasi ARISTA}

Rancangan arsitektur Aplikasi ARISTA (Application of Reporting Information System FTK Undiksha) secara umum diktunjukkan oleh Gambar 4. Arsitektur aplikasi ini menggunakan konsep client server, dimana pengguna dengan menggunakan mobile device akan mengakses server terlebih dahulu untuk mengunduh informasi di database yang sebelumnya sudah dikelola (update) oleh administrator. Sehingga, setiap aplikasi dibuka akan selalu menampilkan informasi terbaru. Dengan menggunakan konsep client server maka akan terjadi sinkronisasi data antara client sebagai pengguna jasa layanan dari server. 


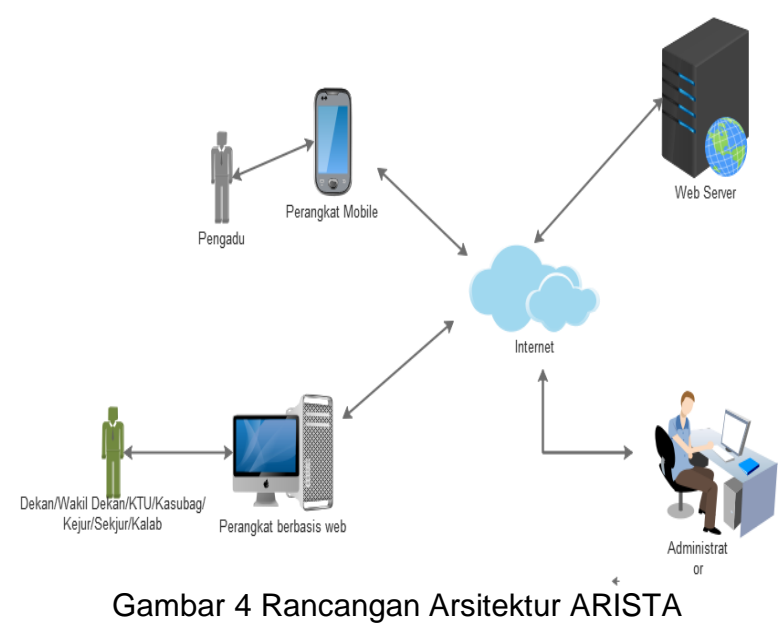

\section{E. ERD}

Berikut merupakan ERD dari Rancangan Aplikasi ARISTA (Application of Reporting Information System FTK Undiksha) yang ditampilkan oleh Gambar 5

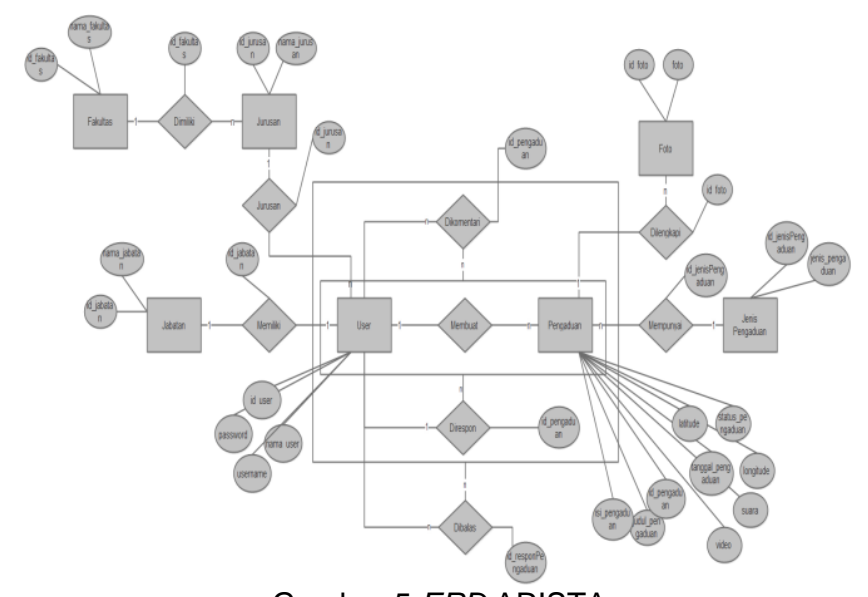

Gambar 5 ERD ARISTA

\section{HASIL DAN PEMBAHASAN}

\section{A. Batasan Implementasi Perangkat Lunak}

Adapun batasan dari perangkat mobile yang digunakan untuk menjalankan aplikasi ARISTA yaitu Android versi 4.1 atau versi diatasnya. RAM minimal $512 \mathrm{MB}$, dan Layar 4 inchi dengan resolusi $854 \times 480$ pixel.

\section{B. Implementasi Arsitektur Perangkat Lunak}

Dalam pengembangan aplikasi ARISTA (Application of Reporting Information System FTK Undiksha) menggunakan arsitektur client - server. Sehingga saat aplikasi dijalankan akan selalu ada proses pertukaran data antara client dan server. Untuk menangani proses pertukaran data tersebut, dibutuhkan beberapa file konfigurasi yang berisi source code untuk menghubungkan antara client dan server. Gambar 6 menunjukkan implementasi arsitektur perangkat lunak dari aplikasi ARISTA 


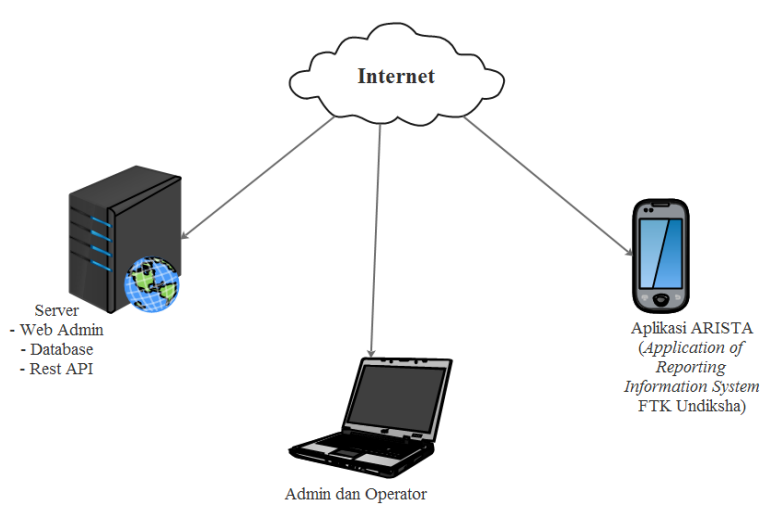

Gambar 6 Implementasi Arsitektur Perangkat Lunak

\section{Implementasi Infrastruktur FTK}

Implementasi Infrastruktur FTK dapat dilihat dari Block Diagram pada Gambar 7

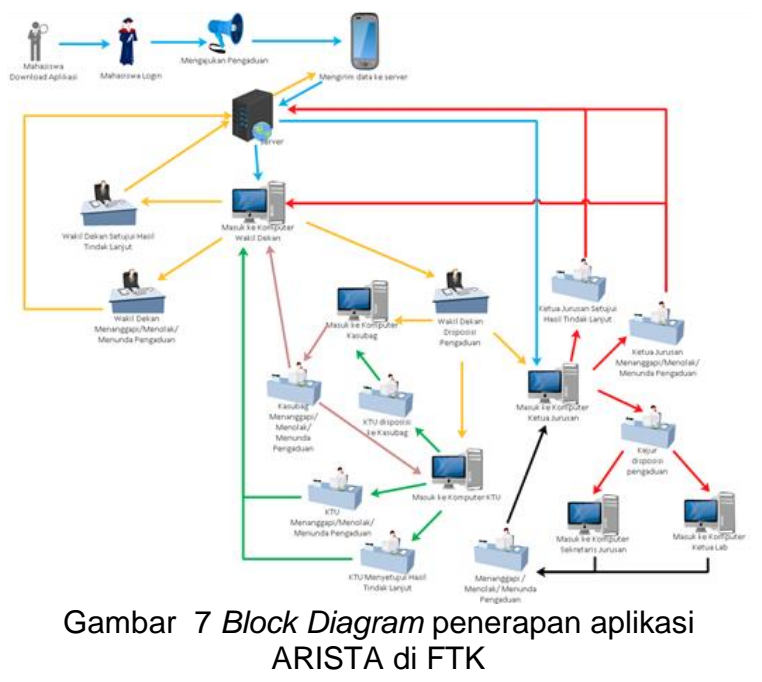

\section{Implementasi Antarmuka Perangkat Lunak}

Adapun implementasi tampilan antarmuka perangkat lunak Aplikasi ARISTA adalah sebagai berikut.

\section{a) Implementasi Antarmuka Splash Screen dan Login.}

Splash Screen merupakan halaman awal ketika aplikasi dibuka. Setelah itu, akan diarahkan ke halaman Login agar user bisa masuk ke aplikasi ARISTA. Implementasi antarmuka ditunjukkan pada Gambar 8 


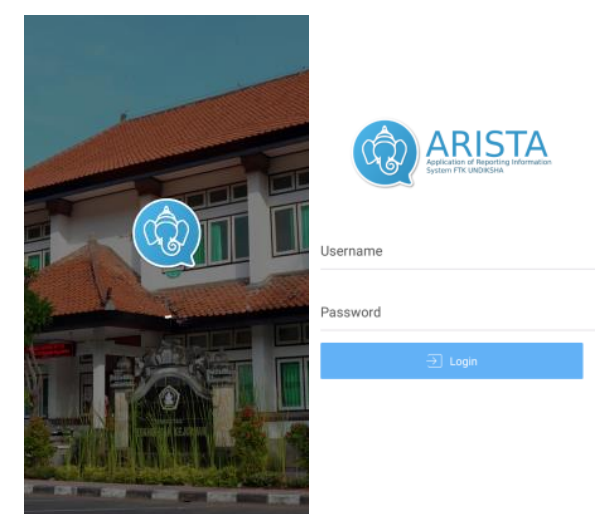

Gambar 8 Implementasi Antarmuka Splash Screen dan Login

\section{b) Implementasi Antarmuka Menu Home dan Pencarian}

Menu Home adalah menu daftar pengaduan yang ada di server. User bisa mencari pengaduan melalui menu. Implementasi antarmuka ditunjukan pada Gambar 9

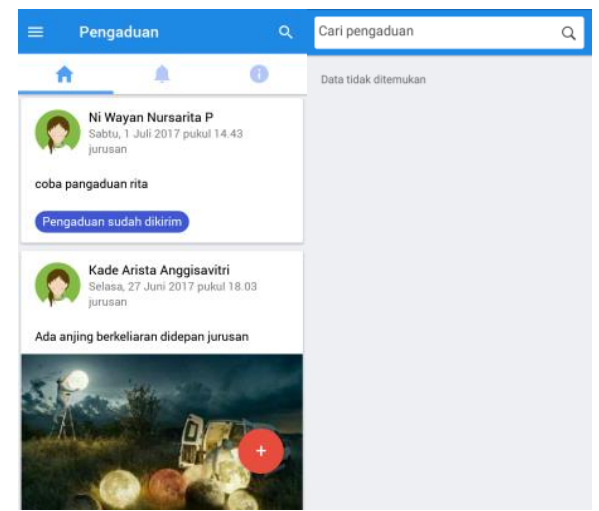

Gambar 9 Implementasi Antarmuka Menu Home dan Pencarian

\section{c) Implementasi Antarmuka Tambah Pengaduan}

Antarmuka tambah pengaduan merupakan halaman untuk user bisa menambah pengaduan dengan melengkapi form tambah pengaduan sesuai dengan cakupan permasalahan yang dipilih. Implementasi antarmuka ditunjukkan pada Gambar 10

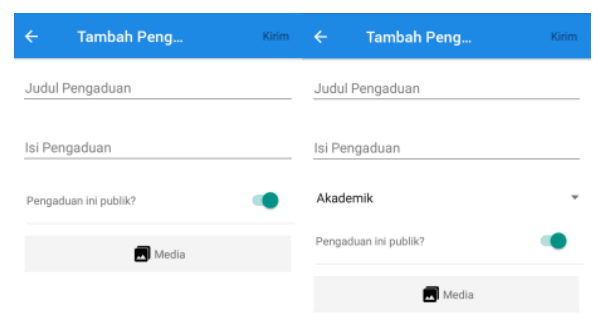

Gambar 10 Implementasi Antarmuka Tambah Pengaduan

\section{d) Implementasi Antarmuka Detail Pengaduan}

Antarmuka Detail Pengaduan merupakan halaman detail pengaduan ketika user menekan salah satu pengaduan. Ketika user ingin membalas respon cukup dengan menekan respon tersebut. Implementasi antarmuka ditunjukkan pada Gambar 11 


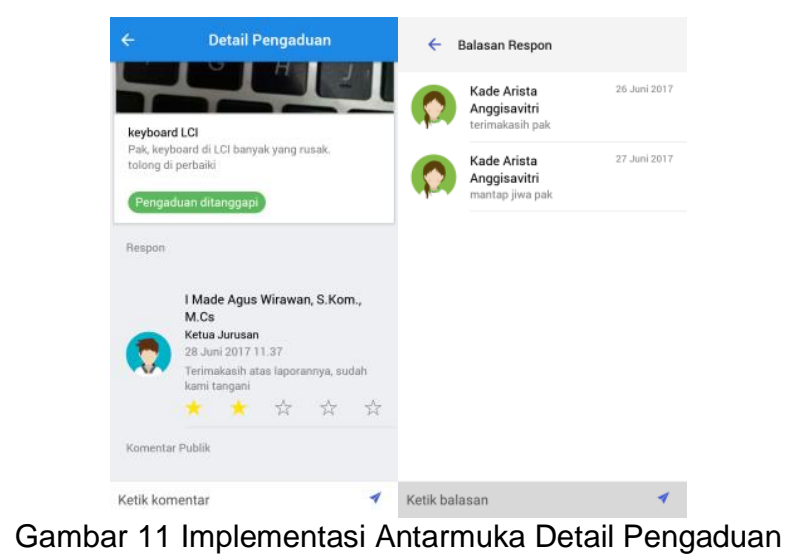

\section{e) Implementasi Halaman Login Web}

Halaman Login Web merupakan halaman pertama ketika user mengakses web. User harus login untuk bisa masuk ke sistem. Implementasi ditunjukkan pada Gambar 12Gambar 12

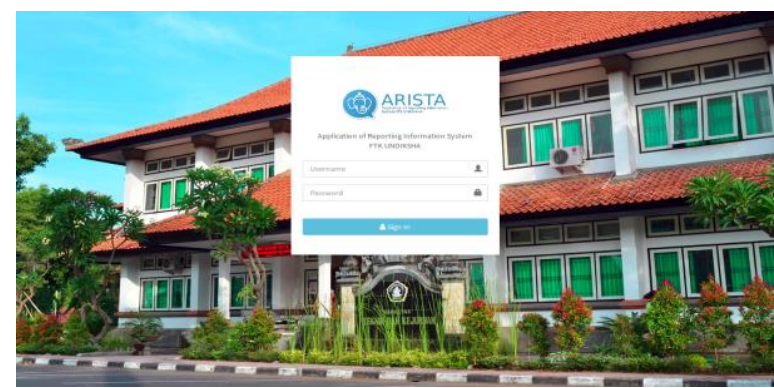

Gambar 12 Implementasi Antarmuka Halaman Login

\section{f) Implementasi Halaman Utama}

Halaman utama merupakan halaman utama yang muncul ketika berhasil login. Implementasi antarmuka ditunjukkan pada Gambar 13

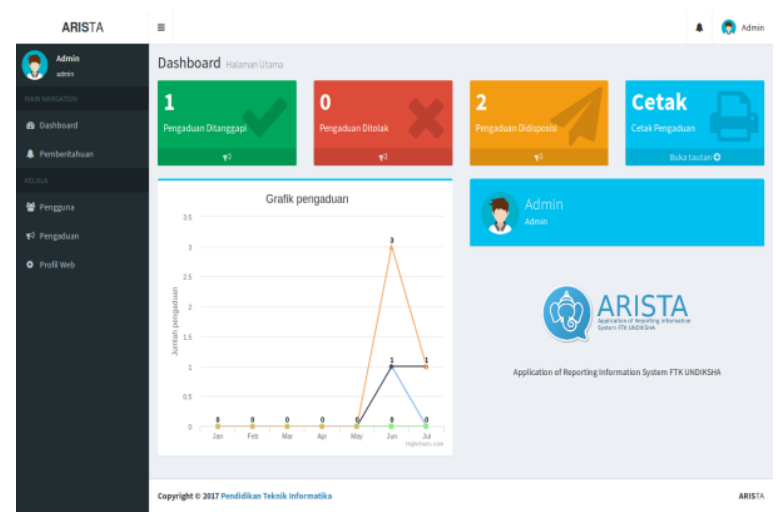

Gambar 13 Implementasi Antarmuka Halaman Utama

\section{g) Implementasi Halaman Daftar Pengaduan}

Halaman daftar pengaduan merupakan halaman yang menampilkan daftar pengaduan sesaui dengan jabatan user. Implementasi ditunjukkan pada Gambar 14 


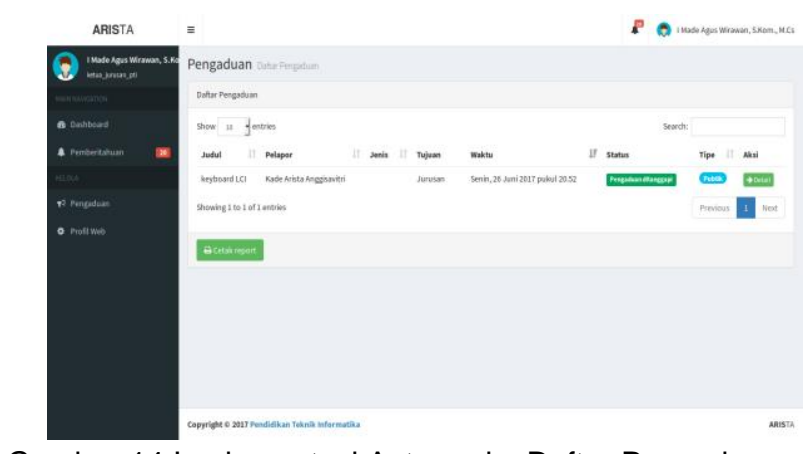

Gambar 14 Implementasi Antarmuka Daftar Pengaduan

\section{h) Implementasi Halaman Detail Pengaduan}

Halaman Detail Pengaduan merupakan halaman detail dari sebuah pengaduan. Disini user bisa melakukan aksi tindak lanjut untuk pengaduan tersebut. Implementasi ditunjukkan pada Gambar 15

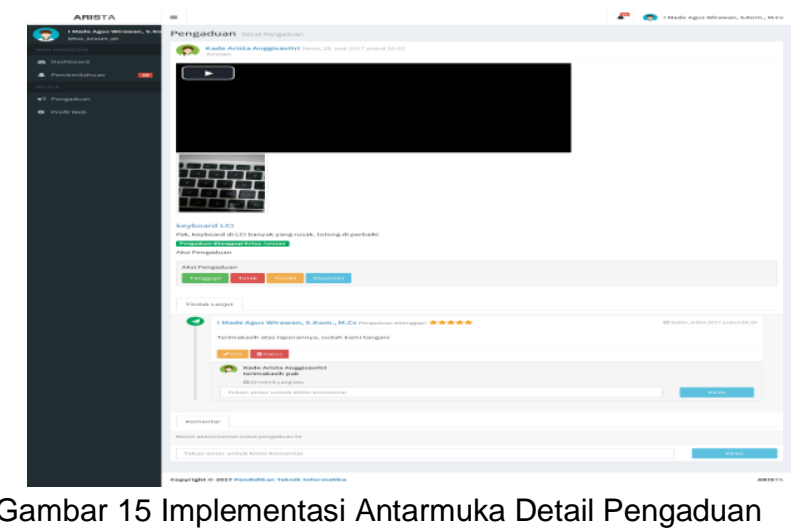

\section{E. Evaluasi Hasil Implementasi Perangkat Lunak}

Aplikasi ARISTA diimplementasikan dengan menggunakan framework React-Native pada aplikasi mobile dan menggunakan framework Laravel pada aplikasi web. Pengadu yang merupakan mahasiswa, dosen, dan pegawai menggunakan aplikasi berbasis mobile. Sedangkan, operator yang merupakan Dekan, Wakil Dekan, KTU, Kasubag, Ketua Jurusan, Sekretaris Jurusan, dan Ketua Lab menggunakan aplikasi berbasis web.

Pengadu harus men-download aplikasi ARISTA terlebih dahulu kemudian Login menggunakan akun SIAK Undiksha. Selanjutnya pengadu bisa menggunakan fitur-fitur yang terdapat pada aplikasi baik itu membuat pengaduan baru, mengedit pengaduan yang telah dibuat, melihat pengaduan pada daftar pengaduan. Ketika pengadu ingin mengirim sebuah pengaduan, pengadu terlebih dahulu harus memilih tujuan daripada pengaduan tersebut. Apakah ke Fakultas atau ke Jurusan, selanjutnya pengadu mengisi formulir secara lengkap, dimulai dari judul pengaduan, isi pengaduan, jenis pengaduan (apabila target pengaduan adalah Fakultas), nama jurusan (apabila target pengaduan adalah Jurusan), memilih status pengaduan apakah publik (bisa dilihat oleh pengadu lain) atau private (hanya dilihat oleh operator dan pengadu itu sendiri). Selanjutnya pengadu dapat menambahkan media berupa foto atau video. Foto dapat diambil langsung menggunakan fitur Kamera, atau mengambilnya dari galeri handphone pengadu dengan menggunakan fitur Gallery. Kemudian Video dapat diambil langsung menggunakan fitur Video. Pengadu dapat melampirkan foto maksimal 5 foto dan melampirkan video maksimal 1 video. Setelah pengaduan berhasil dikirim, pengaduan akan langsung masuk ke akun operator yang dituju.

Selain fitur tambah pengaduan, terdapat juga fitur untuk melakukan edit dan hapus pengaduan. Kemudian, terdapat juga fitur komentar pengaduan dari pengadu lain, membalas respon yang diberikan oleh operator, menutup pengaduan apabila sudah dirasa cukup oleh pengadu, dan memberikan nilai terhadap hasil tindak lanjut. Setiap respon yang diberikan terhadap pengaduan 
tersebut, pengadu yang merupakan pelapor akan mendapatkan informasi sehingga pengadu mengetahui perkembangan dari pengaduan yang dikirim.

Operator yang menerima pengaduan dapat melakukan aksi menanggapi pengaduan, menunda pengaduan, menolak pengaduan, atau mendisposisi pengaduan (untuk operator Wakil Dekan, KTU, dan Ketua Jurusan). Operator yang merupakan sumber dari disposisi akan memberikan persetujuan terlebih dahulu sebelum pengaduan itu sampai pada pengadu. Jadi, dalam hal ini sumber disposisi tetap memantau hasil dari tindak lanjut yang diberikan oleh target disposisi.

\section{F. Hasil Pengujian Perangkat Lunak}

Pelaksanaan pengujian perangkat lunak berlangsung dengan baik dan lancar, baik itu pada saat melakukan Blackbox testing, Whitebox testing, Uji Pengalaman Pengguna, Uji Compatibily dan Uji Keamanan. Tujuan daripada uji blackbox ini adalah untuk menemukan kesalahan pada fitur-fitur aplikasi. Pada saat melakukan uji blackbox, Aplikasi ARISTA (Application of Reporting Information System FTK Undiksha) berfungsi dengan baik dengan mendapatkan hasil sebesar $100 \%$, semua fitur yang terdapat pada Aplikasi ARISTA (Application of Reporting Information System FTK Undiksha) berfungsi dengan baik dan sesuai dengan yang diharapkan. Dimulai dari saat pertama kali dibuka, login, user membuat pengaduan, melihat pengaduan, hingga user melakukan logout.

Selanjutnya, pengujian white box yang dilakukan untuk mengetahui apakah logika yang terdapat pada source code berjalan dengan baik. Hasil pengujian menunjukkan bahwa semua fungsi code yang terdapat pada Aplikasi ARISTA (Application of Reporting Information System FTK Undiksha) dapat berjalan dengan baik dan sesuai.

Pengujian yang ketiga yaitu pengujian pengalaman pengguna. Tujuan dari uji pengalaman user adalah untuk mendapatkan sebuah pengalaman pengguna apakah aplikasi ARISTA dapat digunakan dengan baik sesuai harapan. Pengujian pengalaman pengguna, peneliti mengacu pada metode kuisioner UEQ (User Experience Questionnaire).

Karena sesuatu dapat dikatakan berguna dengan baik apabila kegagalan dalam penggunaannya dapat dihilangkan atau diminimalkan serta memberikan manfaat dan kepuasan bagi pengguna. Ketika sebuah produk atau jasa benar benar dapat dipergunakan dengan baik, pengguna dapat melakukan apa yang dia inginkan dengan cara yang diharapkan serta mampu untuk melakukannya tanpa halangan, keraguan, atau pertanyaan. [13]

Hasil dari pengujian ini adalah Aplikasi ARISTA (Application of Reporting Information System FTK Undiksha) cenderung memiliki impresi positif di setiap kelompok pertanyaan yakni Daya Tarik (2.617), Kejelasan (2.550), Efisiensi (2.375), Ketepatan (2.525), Stimulasi (2.550), dan Kebaruan (2.525). Ketiga, uji pengalaman pengguna mendapatkan hasil yang baik, nilai rata-rata impresi antara $-0,8$ dan 0,8 merupakan nilai evaluasi positif dan nilai-nilai $<-0,8$ merupakan evaluasi negatif. Sehingga dapat disimpulkan bahwa aplikasi ARISTA cenderung memiliki impresi positif (nilai mendekati ke arah 1 dan seterusnya) berturut-turut secara menurun dalam kelompok daya tarik, kejelasan, efisiensi, ketepatan, stimulasi, dan kebaruan. Berdasarkan hasil tersebut dapat disimpulkan bahwa aplikasi ARISTA (Application of Reporting Information System FTK Undiksha) layak digunakan dalam membantu sivitas akademika FTK dalam melaporkan dan menyampaikan keluhan-keluhannya terhadap pelayanan FTK yang kurang baik fisik maupun non fisik kepada pimpinan FTK.

Pengujian selanjutnya yaitu, Uji Compatibility, didapatkan hasil bahwa aplikasi ARISTA mampu berjalan dengan baik pada perangkat mobile yang berbeda dan versi android yang berbeda. Berdasarkan uji Keamanan yang telah peneliti lakukan dengan melakukan 4 kali percobaan menunjukkan hasil bahwa aplikasi ARISTA dapat dikatakan relatif aman.

Untuk hasil pengisian Dokumen UAT, Bapak Dr. Gede Rasben Dantes, S.T., M.T.I selaku Wakil Dekan 1 FTK menyetujui semua form yang terdapat pada Dokumen UAT dan dapat disimpilkan bahwa aplikasi ARISTA (Application of Reporting Information System FTK Undiksha) sudah diterima untuk digunakan di Fakultas Teknik dan Kejuruan sebagai wadah layanan pengaduan secara online.

\section{SIMPULAN DAN SARAN}

Aplikasi ARISTA (Application of Reporting Information System FTK Undiksha) dirancang melalui beberapa tahapan, pertama peneliti melakukan analisis masalah terhadap kekurangan kegiatan audiensi yang diadakan FTK untuk mendengarkan keluhan terkait pelayanan FTK. Dari kekurangan tersebut peneliti menawarkan solusi dikembangkannya aplikasi ARISTA. Selanjutnya peneliti melakukan analisis dengan studi literature, diskusi dan wawancara, serta pengumpulan data 
menggunakan angket. Dari hasil analisis yang dilakukan peneliti selanjutnya merancang kebutuhan fungsional dan non fungsional menggunakan pemodelan use case dan activity diagram, dan menggunakan arsitektur client-server dalam proses pertukaran data dan informasi. Kemudian peneliti melakukan perancangan perangkat lunak mulai dari batasan perangkat lunak, struktur navigasi, antarmuka, arsitektur perangkat lunak, dan struktur data sebelum mengimplementasikannya.

Aplikasi ARISTA (Application of Reporting Information System FTK Undiksha) diimplementasikan dengan menggunakan framework React-Native, sehingga dapat menghasilkan aplikasi yang mampu berjalan di berbagai platform perangkat mobile. Hanya saja saat ini Aplikasi ARISTA belum bisa berjalan di iOS karena dibutuhkan perangkat lain seperti MAC OS untuk melakukan complier app. Aplikasi ARISTA berjalan secara online, jadi membutuhkan jaringan internet untuk menjalakan aplikasi ini.

Pengujian Aplikasi ARISTA (Application of Reporting Information System FTK Undiksha) dilakukan dengan 5 jenis pengujian dan mendapatkan hasil sebagai berikut. Pertama, pengujian blackbox mendapatkan hasil sebesar $100 \%$, dimana semua fitur pada aplikasi berjalan sesuai dengan yang dirancang sebelumnya.dalam artian fitur-fitur yang ada pada aplikasi dapat berjalan dengan baik. Kedua, saat pengujian whitebox semua source code berserta logika-logika yang ada di aplikasi ARISTA (Application of Reporting Information System FTK Undiksha) dapat berjalan dengan baik dan tidak ada error yang terjadi. Ketiga, uji pengalaman pengguna mendapatkan hasil yang baik, nilai ratarata impresi antara $-0,8$ dan 0,8 merupakan nilai evaluasi positif dan nilai-nilai $<-0,8$ merupakan evaluasi negatif. Sehingga dapat disimpulkan bahwa aplikasi ARISTA cenderung memiliki impresi positif (nilai mendekati ke arah 1 dan seterusnya) berturut-turut secara menurun dalam kelompok daya tarik, kejelasan, efisiensi, ketepatan, stimulasi, dan kebaruan. Dengan begitu, dapat disimpulkan aplikasi ARISTA (Application of Reporting Information System FTK Undiksha) layak untuk digunakan. Selanjutnya keempat, uji compatibility mendapatkan hasil aplikasi ARISTA dapat diimplementasikan di perangkat mobile yang berbeda-beda. Uji yang terakhir adalah uji keamanan dengan SQL Injection sebanyak 4 kali. Hasilnya menunjukkan bahwa aplikasi ARISTA (Application of Reporting Information System FTK Undiksha) relatif aman.

Berdasarkan hasil penelitian pengembangan dan kesimpulan, dapat disarankan kepada pembaca dan atau peneliti bahwa dalam pengembangan selanjutnya diharapkan dapat dilakukan uji implementasi pada platform iOS. Karena pada implementasi peneliti kekurangan perangkat untuk melakukan compiling aplikasi untuk sistem operasi iOS. Selanjutnya, membuat aplikasi berbasis mobile untuk operator. Besar harapan aplikasi ini bisa dikembangkan untuk digunakan oleh Fakultas lain atau bahkan digunakan untuk Universitas Pendidikan Ganesha.

\section{DAFTAR PUSTAKA}

[1] Undiksha, "Universitas Pendidikan Ganesha," www.undiksha.ac.id, 2017. [Online]. Available: http://undiksha.ac.id/tentang-undiksha/selayang-pandang/.

[2] Ftk, "Fakultas Teknik dan Kejuruan," 2017. [Online]. Available: ftk.undiksha.ac.id: http://ftk.undiksha.ac.id/visi-dan-misi/.

[3] N. P. Rustrini, I. K. R. Arthana, and G. S. Santyadiputra, "A DESCRIPTIVE SURVEY ON SMARTPHONES FEATURES FOR SUPPORTING THE ACADEMIC ACTIVITIES," J. Pendidik. Teknol. dan Kejuru., vol. 23, 2016.

[4] J. E. Istiyanto, Pemrograman SmartPhone Menggunakan SDK Android dan Hacking Android. Yogyakarta: Graha IImu, 2015.

[5] V. Chandra, Pintar Pemrograman Aplikasi iPhone \& iPad. Yogyakarta. Yogyakarta: Penerbit Andi, 2013.

[6] N. Safaat, Rancang Bangun Aplikasi Multi Platform. Bandung: Informatika, 2015.

[7] A. W. Putra, "React Native - Framework Besutan Facebook Untuk Kembangkan Aplikasi Native Android dan iOS Dengan JavaScript," teknojurnal.com, 2105. [Online]. Available: https://teknojurnal.com/react-native-framework-besutan-facebook-untuk-kembangkan-aplikasinative-android-dan-ios-dengan-javascript/.

[8] GeekyAnts, "NativeBase," docs.nativebase.io, 2017. [Online]. Available: https://docs.nativebase.io/.

[9] A. Rohman, "Mengenal Framework 'Laravel ' ( Best PHP Frameworks For 2014 )," ilmuti.org, 2014. 
[10] I. A. Putra and S. Hartini, "Sistem Pendukung Keputusan Berbasis Client Server Untuk Penentuan Biaya Pembangunan Rumah (Studi Kasus Pada PT. Buana Nata Loka).," J. IImy Komput., vol. 4 No. 1, 2011.

[11] A. Hidayat, S. D. Rizki, and D. Saputra, "PERANCANGAN SISTEM INFORMASI PENGOLAHAN NILAI BERBASISKAN WEB PADA SEKOLAH MENENGAH ATAS NEGERI 5 BUKITTINGGI DENGAN MENGGUNAKAN BAHASA PERMROGRAMAN PHP," vol. 6, no. 2, pp. 40-44, 2016.

[12] P. Krisnayani, I. K. R. Arthana, and I. G. M. Darmawiguna, "Analisa Usability Pada Website UNDIKSHA Dengan Menggunakan Metode Heuristic Evaluation," Kumpul. Artik. Mhs. Pendidik. Tek. Inform., vol. 5, 2016. 